\title{
2016 Norbert Wiener Prize in Applied Mathematics
}

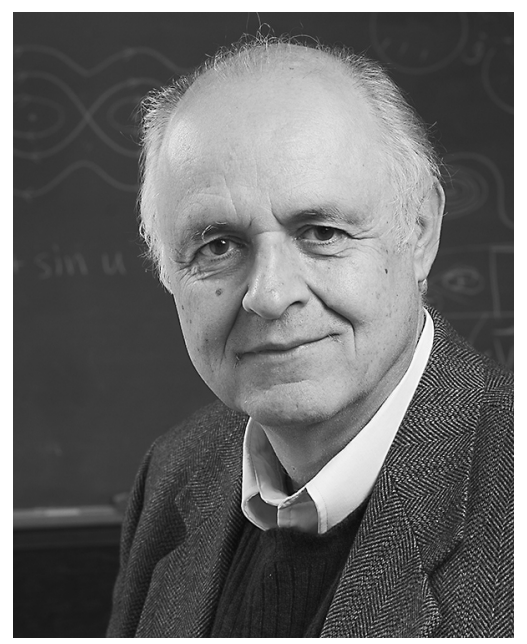

Constantine Dafermos
CONSTANTINE DAFERMOS was awarded the 2016 AMS-SIAM 2016 Norbert Wiener Prize in Applied Mathematics at the 122nd Annual Meeting of the AMS in Seattle, Washington, in January 2016.

\section{Citation}

The 2016 Norbert Wiener Prize in Applied Mathematics is awarded to Professor Constantine M. Dafermos for his foundational work in partial differential equations and continuum physics. Professor Dafermos is recognized for his seminal contributions to the theory of nonlinear conservation laws and its application to continuum mechanics, gas dynamics, and nonlinear elasticity. His work has advanced the research areas of fading memory, $\mathrm{N}$-waves, periodicity and decay, dissipation, entropy, and compensated compactness; it has directed applications to two-phase flows, thermoelasticity, viscoelastic materials, and both sonic and subsonic flows. He has introduced several fundamental concepts such as the methods of relative entropy, generalized characteristics, wave-front tracking, and the entropy rate criterion for the selection of admissible wave fans.

\section{Biographical Sketch}

Constantine Dafermos was born in Athens, Greece, in 1941. He received a diploma in civil engineering from the National Technical University in 1964 and $\mathrm{a} \mathrm{PhD}$ in mechanics from Johns Hopkins

For permission to reprint this article, please contact: reprint-permission@ams.org.

DOI: http://dx.doi.org/10.1090/noti1359
University in 1967. After teaching for three years at Cornell University, he moved to Brown University in 1971, where he is currently professor of applied mathematics. His work lies at the interface between continuum mechanics and partial differential equations.

\section{Response from Constantine Dafermos}

I am deeply honored to receive 2016 Norbert Wiener Prize in Applied Mathematics but also am humbled by the prospect of joining the company of such distinguished earlier recipients. I feel that I am sharing the award with scores of teachers, colleagues, and students who shaped me as a scientist and provided, over the years, invaluable support and inspiration. The list is very long, so I shall only mention those who departed way too early: my wife Stella and Ron DiPerna.

\section{About the Prize}

The Norbert Wiener Prize in Applied Mathematics is awarded every three years to recognize outstanding contributions to applied mathematics in the highest and broadest sense (until 2001, the prize was awarded every five years). Established in 1967 in honor of Norbert Wiener (1894-1964), the prize was endowed by the Department of Mathematics of the Massachusetts Institute of Technology. The prize is given jointly by the AMS and the Society for Industrial and Applied Mathematics (SIAM). The recipient must be a member of one of these societies and a resident of the United States, Canada, or Mexico. The prize carries a cash award of US\$5,000.

The recipient of the Norbert Wiener Prize in Applied Mathematics is chosen by a joint AMS-SIAM selection committee. For the 2016 prize, the members of the selection committee were the following individuals.

- Walter Craig

- Ronald A. DeVore

- Charles L. Epstein (Chair) 
The complete list of recipients of the Norbert Wiener Prize in Applied Mathematics follows.

1970 Richard E. Bellman

1975 Peter D. Lax

1980 Tosio Kato, Gerald B. Whitham

1985 Clifford S. Gardner

1990 Michael Aizenman, Jerrold E. Marsden

1995 Hermann Flaschka, Ciprian Foias

2000 Alexandre J. Chorin, Arthur T. Winfree

2004 James Sethian

2007 Craig Tracy, Harold Widom

2010 David L. Donoho

2013 Andrew Majda

2016 Constantine Dafermos
American Mathematical Society
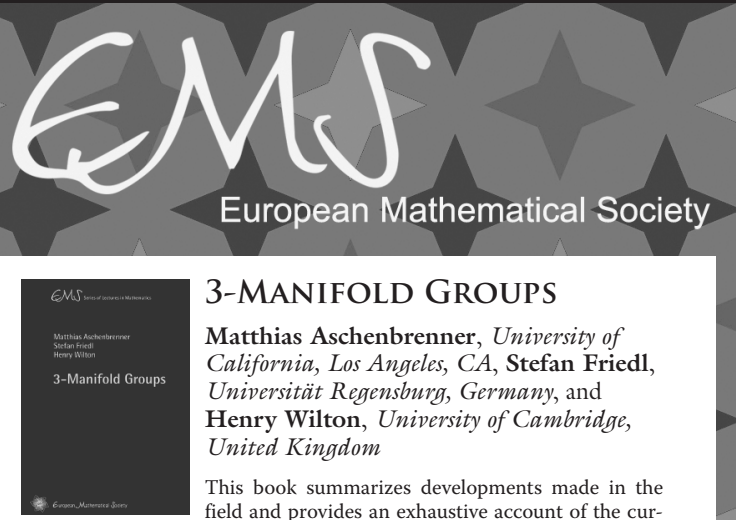

\section{3-MANIFOLD GROUPS}

Matthias Aschenbrenner, University of California, Los Angeles, CA, Stefan Friedl, Universität Regensburg, Germany, and Henry Wilton, University of Cambridge, United Kingdom

This book summarizes developments made in the field and provides an exhaustive account of the current state of the art of 3-manifold topology, especially focusing on the consequences for fundamental groups of 3-manifolds.

EMS Series of Lectures in Mathematics, Volume 20;2015; 230 pages; Softcover; ISBN: 978-3-037/ 9-154-5; List US\$48;AMS members US $\$ 38.40$; Order code EMSSERLEC/20

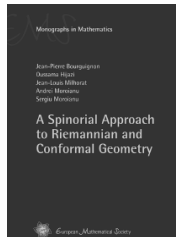

\section{A SPINORIAL APPROACH} TO RIEMANNIAN AND CONFORMAL GEOMETRY

Jean-Pierre Bourguignon, Institut des Hautes Études Scientifiques, Bures-surYvette, France, Oussama Hijazi, Université de Lorraine, Vandauvre-lès-Nancy, France, et al.

The book gives an elementary and comprehensive introduction to Spin Geometry, with particular emphasis on the Dirac operator, which plays a fundamental role in differential geometry and mathematical physics.

EMS Monographs in Mathematics, Volume 6; 2015; 462 pages; Hardcover; ISBN: 978-3-037I9-136-I; List US\$87;AMS members US\$69.60; Order code EMSMONO/6

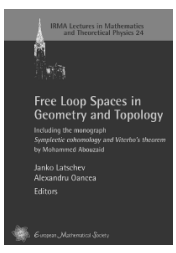

FREE LOOP SPACES IN GEOMETRY AND TOPOLOGY

INCLUDING THE MONOGRAPH "SYMPLECTIC COHOMOLOGY AND VITERBO'S THEOREM"

Lafayette, IN

Fabrice Baudoin, Purdue University, West

This book facilitates communication between topologists and symplectic geometers thinking about free loop spaces and also begins to explore the new directions of research that have emerged recently.

IRMA Lectures in Mathematics and Theoretical Physics, Volume 24; 20I5; 500 pages; Hardcover; ISBN: 978-3-037I 9-153-8; List US $\$ 87 ;$ AMS members US $\$ 69.60$; Order code EMSILMTP/24

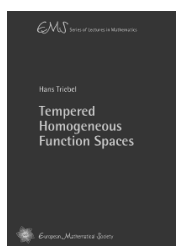

TEMPERED HOMOGENEOUS FUNCTION SPACES

Robert J. Marsh, University of Leeds, United Kingdom

This book deals with homogeneous function spaces of Besov-Sobolev type within the framework of tempered distributions in Euclidean $n$-space based tempered distributions in Euclidean
on Gauss-Weierstrass semi-groups.

EMS Series of Lectures in Mathematics, Volume 21; 2015; 143 pages; Softcover; ISBN: 978-3-037I9-155-2; List US $\$ 38$; AMS members US\$30.40; Order code EMSSERLEC/2I

Publications of the European Mathematical Society (EMS). Distributed within the Americas by the American Mathematical Society.

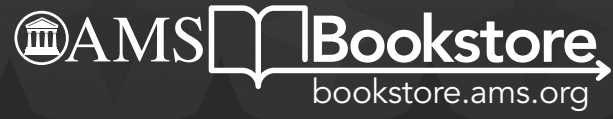

